\title{
O corpo do improvisador
}

\section{Raquel Valente de Gouvêa ${ }^{1}$}

O que pode o corpo do improvisador? Metamorfosear-se em corpo-movimento, prolongando-se para além do desenho que cria no espaço-tempo, ele então se transmuta em corpo sutil, energético, paradoxal. Neste artigo apresentamos uma reflexão sobre o corpo do improvisador nos entrelugares da dança, teatro e filosofia.

PALAVRAS-CHAVE: Corpo, consciência-corpo, improvisação.

\section{Abstract}

What can the body of the improviser? To metamorphose into body-movement, extending itself beyond the design it

creates in the space-time, then to transmute into a subtle body, energetic, paradoxical. This article presents a reflection on the body of the improviser, in the spaces between dance, theater and philosophy.

KEYWORDS: Body, body awareness, improvisation. 


\section{Corpo metamorfose}

O corpo ${ }^{2}$ do improvisador que cria a dança no aqui-agora é um corpo mutante, que continuamente devém outro, assumindo provisoriamente novas formas em corporeidades diversas. Um tal corpo em estado de criação contínua abrese às conexões virtuais imponderáveis e imprevisíveis que habitam o invisível, o plano microscópico da experiência, e é por elas afetado e modificado de forma não consciente - o que não exclui a possibilidade de este processo tornar-se consciente. Este corpo surge no momento em que o improvisador ultrapassa o vivido encarnado e os rastros de seus condicionamentos até tornar-se permeável ao não-vivido virtual que, envolvendo o primeiro, lança-o para além de seus limites.

Pensar este corpo é também vivenciá-lo e, desta maneira, penetrar camadas mais profundas da experiência do improvisador; entretanto, não se pretende aqui definir o que este corpo é, mas investigar o que ele pode e como tornálo ainda mais potente para criar a dança. A pesquisa da improvisação de dança ${ }^{3}$ me levou ao plano das intensidades virtuais, das forças que compõem os corpos; das relações que eles constroem e desconstroem continuamente; plano da intuição sensível, da heterogeneidade das matérias expressivas, da imanência da dança. Foi, então, preciso reaprender a olhar o corpo a fim de poder capturá-lo em sua contínua metamorfose, para percebê-lo como ele se mostra naquilo que não aparece, que se esconde ou se esquiva de uma percepção trivial, ou seja, foi preciso um esforço para ultrapassar o limite visível e macroscópico de um corpo

2

A noção de corpo aqui utilizada implica necessariamente a relação com a mente, portanto, quando uso a palavra corpo neste artigo estou dizendo corpomente. 0 conceito corpomente está inserido na perspectiva da continuidade entre corpo e mente na experiência cognitiva e é frequentemente empregado pela corrente teórica chamada embodied cognition.

3 Inicio a pesquisa da improvisação de dança com dançarinos e atores em 1996 em Campinas, SP. Em 2004 conclui mestrado no qual apresento uma proposta de preparação do improvisador chamada prática corporeoenergética. $O$ presente artigo faz parte da pesquisa de doutorado concluída em 2012 na Faculdade de Educação da Unicamp. que se move no espaço-tempo dirigido pela consciência, para percebê-lo como corpo esteticamente recriado nas conexões intensivas que ele compõe com os outros e que o compõem, as quais penso serem capturadas pela intuição sensível sustentada por uma conscência-corpo.

A ideia de uma consciência-corpo resulta de elaboração a partir do conceito de "consciência do corpo" (awareness) proposto pelo filósofo português José Gil (2004) que diz da experiência de movimento do dançarino. Para mim, uma consciência impregnada de corpo como Gil propõe é já uma consciência-corpo, que provoca uma atitude, um estado outro de presença psicofísica que o improvisador necessita para estar na experiência ${ }^{4}$, a qual revela a perfeita e direta coordenação entre corpo e pensamento. Uma atitude que entendo não ser totalmente consciente no dançarino-improvisador, por isso, a necessidade de ultrapassar a noção de percepção como um estado da consciência (Husserl, 2001). A percepção associada a uma consciênciacorpo, ao incluir as micropercepções inconscientes, obscuras e confusas, ultrapassa o limite da experiência consciente habitual. Penso que uma consciência-corpo expressa melhor a ausência de intencionalidade e a presença determinante das intensidades inconscientes que afetam a experiência, provocando a mudança na forma de perceber do improvisador.

Ficou também evidente em minha pesquisa que o corpo em estado de criação de dança difere do corpo comum ou cotidiano com o qual experimentamos a vida; assim como que aquele corpo não pode ser apreendido pela perspectiva de um corpo-organismo-vivo, nem mesmo pelas explicações físico-químicas oferecidas pela fisiologia, anatomia e motricidade. Não nos importa também um corpo subjetivado, reagente-reativo, condicionado pelas memórias ou deter-

4 Penso o conceito de experiência como em Jorge Bondia Larossa (2002), ou seja, a experiência como aquilo que nos acontece, nos afeta e nos toca aqui e agora. 
minado fortemente pelas pulsões. Como veremos adiante, este corpo em estado de criação de dança aproxima-se da noção de corpo intensivo ou corpo-semórgãos (CsO) proposta por Gilles Deleuze e Felix Gattari, até encontrar melhor abrigo na noção de corpo paradoxal de José Gil. Mas antes de lá chegarmos, algumas reflexões são necessárias.

O corpo comum, cotidiano, com e no qual experimentamos a vida, é um corpo útil, necessário; nele e por ele efetuamos todas as ações cotidianas, que não necessitam da atenção contínua da autopercepção. Este corpo mostra ao mundo a pessoa como ela é em suas atividades e necessidades triviais e, neste sentido, é diferente do estado corporal desejável e necessário ao artista tanto no momento da criação como na preparação ou apresentação da obra, e por isto as técnicas empregadas para a realização das ações cotidianas diferem das técnicas corporais em arte.

Eugenio Barba (1936-), mestre da arte teatral e fundador da ISTA - Escola Internacional de Antropologia Teatral (1995), afirma que as técnicas cotidianas empregadas para as ações comuns resultam de condicionamentos impostos pela educação em amplo sentido, processo este que o autor chama "aculturação coletiva". Barba (1995), assim como Rudolf Laban (1978), entende que para o corpo realizar as ações cotidianas não é necessário um grande investimento de energia psíquica e física, pois, nestas atividades há uma economia do esforço, isto é, um mínimo dispêndio de energia na execução das ações cotidianas. Por outro lado, as ações cenicamente construídas demandam, para Barba, uma qualidade diferente de esforço psicofísico, que entendo ser uma presença psicofísica modificada, que aumenta interna e externamente as potências expressivas do corpo do artista.

A pesquisa proposta pela Antropologia Teatral visava encontrar os princípios básicos do trabalho de ator recorrentes em diferentes culturas, pois, segundo
Barba: “Eles são um meio de desnudar o corpo de hábitos cotidianos, para evitar que ele seja apenas um corpo humano condenado a se parecer consigo mesmo, para apresentar e representar somente a si mesmo" (1995, p.16). Desnudar o corpo comum para revelar corpos de expressão, nos quais o imperativo dado pelos gestos significados na experiência vivida não mais condicionam uma expressividade naturalizada pelos hábitos e pela repetição do mesmo. Desvelar um corpo muitas vezes desconhecido, por meio do qual o ator, dançarino e improvisador possam manifestar a novidade, o imprevisível que se esquiva entre as ações conhecidas e vivenciadas. E para acessá-lo, ou melhor, para que aconteça a metamorfose que transforma um corpo comum em um corpo cenicamente modificado pela artificialidade do gesto, o artista se vale de técnicas "extra-cotidianas" (Barba, 1995) para obter os resultados estéticos desejados em suas criações.

Entendo que em ambas as situações, cotidiana e cênica, trata-se de desvelar a diferença no plano da presença psicofísica do artista (mesmo admitindo que esta noção não diga com clareza a experiência que tenho em mente); a diferença que surge do envolvimento e presença total à experiência que o afeta e o toca.

A eficiência do corpo comum está ligada aos aprendizados assimilados ao longo da vida, às muitas repetições que realiza nas atividades simples ou complexas, as quais estão também diretamente relacionadas ao meio cultural e aos pressupostos e opiniões que orientam a percepção neste e deste meio em que vive e que aprende a ocupar como um corpo-objeto ou mesmo como um corpo-sujeito. Neste corpo, as ações que compõem o comportamento são predominantemente automatizadas, mostrando a força e a resistência de um corpo continuamente estratificado pelas determinações exteriores e pelas marcas do vivido. Um corpo treinado, adestrado e condicionado a refazer os caminhos co- 
nhecidos mesmo diante da diversidade de relações possíveis que a vida lhe oferece tem uma utilidade prática importante na sustentação e estabilidade do corpomente, entretanto, para a criação da dança estas marcas são obstáculos ao surgimento da novidade e mesmo de uma resignificação autêntica do vivido ${ }^{5}$.

O corpo comum, em geral, é percebido pelo homem comum como uma presença de fundo da qual o sujeito é consciente de forma intermitente, ou seja, no dia a dia o todo e as partes deste corpo aparecem em primeiro plano para a consciência em intervalos irregulares e descontínuos. A descontinuidade da auto-percepção permite, por exemplo, que a consciência se distancie da realização das ações para se concentrar na atividade reflexiva e racional, criando a falsa impressão de uma desarticulação entre pensamentos e ações. Estas maneiras de existir que segregam um corpo comum nos afastam da presença expressiva, da integridade corpomente, do acoplamento perfeito entre pensamento e ação. Não encontro nestes corpos as qualidades necessárias para pensarmos o corpo do improvisador, o corpo que pode intuir diretamente a dança na atmosfera da criação do improviso e que é sensível e atento às forças afetivas que se movem interna e externamente nos entrelugares da dança.

Para além do corpo comum, parcialmente consciente, e do corpo físico-mecânico, biologicamente entendido por meio de órgãos integrados, o corpo do artista, sobretudo nas artes corpóreas, transmutase em corpo sutil, vibrátil, fluido e nebuloso. A metamorfose é já uma mudança intensiva na percepção, um excesso que faz jorrar a profundidade deste corpo até a superfície: uma passagem que permite a atualização de forças expressivas que se agitam e que reivindicam sua forma no

5 O novo e a novidade são potencialidades co-presentes que podem ou não ser atualizadas pelo improvisador, dependendo de muitos fatores, entre eles, a quebra dos condicionamentos físico-motores e psíquicos auto-replicantes. Entende-se por novo qualquer composição de forças que surge como diferença tanto do ponto de vista estético da dança quanto da experimentação dos improvisadores. O novo, para ser potente e afirmativo, deve provocar encontros e desvios sem que os sentidos da obra se percam, sem que o improvisador rompa com a imanência do improviso. mundo. Um corpo em arte nos leva a uma mudança real no modo de ver, de perceber e de existir.

\section{Corpo luminoso, intensivo, corpo sem órgãos.}

A prática em sala de trabalho com dançarinos e atores associada a minha vivência pessoal da improvisação orientaram o meu olhar para uma perspectiva ampliada do corpo do improvisador. Durante o mestrado (Gouvêa, 2004) a investigação deste corpo se deu de uma maneira rizomática, que me permitiu encontrar conexões improváveis entre arte, ciência, psicologia, antropologia, terapias alternativas. Em todos estes territórios do conhecimento humano e também das sabedorias de diferentes culturas existem rastros de uma compreensão do corpo energético e sutil que entendo ser o corpo criador do improvisador. Entretanto, foi na pesquisa de doutorado (Gouvêa, 2012) que encontrei uma maneira mais instigante para pensá-lo: a filosofia.

Pensando este corpo outro, Deleuze dialoga com a ideia de corpo-sem-órgãos, o corpo do ator de Antonin Artaud: "Para além do organismo, mas também como limite do corpo vivido, existe aquilo que Artaud descobriu e nomeou: corpo sem órgãos" (2007, p. 24). Em Mil Platôs encontramos o seguinte texto: "O organismo não é o corpo, o $\mathrm{CsO}$, mas um estrato sobre o $\mathrm{CsO}$, quer dizer um fenômeno de acumulação, de coagulação, de sedimentação que lhe impõe formas, funções, ligações, organizações dominantes e hierarquizadas, transcendências organizadas para extrair um trabalho útil" (Deleuze \& Guattari. 1996, p.21).

O corpo-sem-órgãos $(\mathrm{CsO})$ está "para além do organismo", isto é, ele o ultrapassa ao se contrapor à organização dos órgãos definida pela noção de organismo, aqui entendido como um "conjunto regulado de órgãos submetidos a um princípio de unidade orgânica, uma forma que aprisiona o corpo numa organização corporal definida" (Machado, 2009, p.233). Mas ele também é o limite do corpo fenomenológico, corpo 
objetivo-subjetivo, encarnado, vivo, do qual teríamos apenas uma percepção parcial dirigida pela intencionalidade da consciência cognitiva, como pretende a explicação husserliana. Ou ainda, avançando nesta concepção, o corpo próprio de Merleau-Ponty, vivido, visível e vidente, meio de comunicação e interação com o mundo, orientado por uma consciência engajada no mundo prático, por uma intencionalidade que é ao mesmo tempo perceptiva e motora. Entendo que em ambos os casos, o corpo fenomenológico não nos permite pensar o que está para além do organismo e entre visível e vidente; aquilo que escapa à intencionalidade da consciência, mas que pode ser apreendido diretamente pela intuição sensível: as intensidades das pequenas-percepções que se agitam no plano de imanência e que afetam e modificam o corpo comum e as relações deste com o mundo, facilitando a metamorfose para um corpo feixe de forças, corposem-órgãos, intensivo e vibrante.

Deleuze e Artaud afirmam a necessidade de abandonarmos o organismo como ideia, explicação e, assim, minimizarmos a pregnância deste pensamento sobre o corpo na percepção direta que temos dele. Não se trata de teorizar sobre o corpo, mas de chamar a atenção para os acontecimentos singulares que surgem de determinadas intervenções sobre o corpo empírico: da descamação dos estratos à intensificação e circulação das energias interiores, à reversão destas forças ao exterior, o corpo energético é libertado, tornando ativo, potente.

Intensificar o corpo luminoso é quebrar a sua casca ou criar brechas na percepção para, então, retirar os estratos e perder a forma humana, isto é, abandonar o corpo organismo, desvelar-se, a fim de libertar o corpo intensivo. Para que o ator se torne um atleta afetivo, ele precisa se desfazer das amarras que o aprisionam em um corpo comum, em um corpo dócil, organizado, adestrado. Em Artaud este pensamento é tornado prática por meio da interferência nos padrões de respiração.

Desafio semelhante se impõe aos dançarinos-improvisadores: minimizar o vivido do corpo que se manifesta como tendências de movimento/pensamento que limitam a criação da dança ao distanciá-lo das singularidades dos acontecimentos na imanência. Eles, então, se colocam em experimentação de forma rigorosa e aprendem a se observar (atenção incorporada) para, enfim, reconhecerem e interferirem nos padrões físicos e mentais que restringem o potencial criativo da dança. O mesmo se aplica para as tendências recorrentes em um coletivo.

Não se trata, entretanto, de negar os condicionamentos, os hábitos, mas de despotencializá-los; por outro lado, significa aprender a agarrar a diferença que se esquiva da percepção comum nos entrelugares do vivido, compondo com ela novas possibilidades de movimento, criando brechas e bifurcações inusitadas. O corpo dilatado que surge à medida que os estratos do corpo comum são retirados e os automatismos minimizados, retém intuitivamente a diferença que surge dos encontros e misturas das pequenas-percepções, atualizandoa prontamente no improviso. O improvisador aprende a quebrar a casca, mas ela sempre voltará a se formar em outros estratos, por isso a necessidade de conhecimento rigoroso destes processos.

\section{Desfazer o organismo nunca foi ma- tar-se, mas abrir o corpo a conexões que supõem todo um agenciamento, circuitos, conjunções, superposições e limiares, passagens e distribuições de intensidade, territórios e desterri- torializações medidas a maneira de um agrimensor. (Deleuze \& Guattari, 1996, p. 22).}

Desfazer os estratos, minimizando o seu poder de pré-determinar a ação para libertar a presença do corpo intensivo; desarticular os estratos sobre o $\mathrm{CsO}$ que lhe impedem de fluir, de emergir do espaço interior às superfícies da pele; "arrancar a consciência do sujeito para fazer dela um meio de exploração" (1996, p.22), e do inconsciente retirar toda significância para que ele seja realmente produtivo, são ousadias necessárias para aquele que cria. Por 
outro lado, é preciso manter o suficiente do organismo, isto é, dos estratos, das explicações, subjetivações e objetivações, a fim de não se perder no caos das intensidades e dele voltar com a dança em um corpo já transformado. Portanto, é preciso um saber-fazer, um conhecimento prático, que não decorre meramente da aplicação de técnicas, mas da experimentação constante e rigorosa, instado desde as profundidades do espaço interior do corpo e em direção à ação no espaço-tempo exterior. E como há risco neste processo é preciso aprender a dosar as interferências e o modo de operá-las sobre si mesmo e com o outro, fazendo uso da prudência ao longo de todo o processo de criação-revelação do $\mathrm{CsO}$. Processos estes que jamais se concluem de fato, pois são muitos os planos afetivos e muitos os $\mathrm{CsO}$ a serem libertados.

Um corpo sem extensão, corpos virtuais, nos quais circulam sensações e afetos, onde se movem forças e apenas forças. Conectados ao corpo comum não podem, entretanto, ser percebidos por um olhar sem horizonte, impotente para estar no devir, para entrar no caos da criação. O CsO é, na verdade, um plano de forças que produz e distribui intensidades em um espaço nãoextenso, ou como Deleuze e Guattari o definem: um spatium intensivo.

Por fim, o CsO não é um corpo transcendente, separado, ideal. Não é tampouco um corpo decalcado do corpo comum, mas um corpo que é despertado pela potência de desejar, de estar na imanência, de penetrar o devir, de ser um no fluxo do movimento da vida. Todos nós temos um ou vários, poucos se mantêm a eles conectados; o artista, entretanto, não tem escolha, ele sabe intuitivamente que precisa criá-lo para acessar as forças que o levarão à criação da obra, para tanto, se vale de técnicas e rituais e muita experimentação. É este corpo que Artaud consagra ao ator e Deleuze e Guattari à arte e ao artista de maneira geral, uma vez que para estes autores "toda arte é captura de forças e não reprodução ou invenção de formas" (Machado, 2009, p. 233). Sendo o CsO o plano energético do corpo é com ele que o improvisador cap- tura as forças e as trans-forma em gestos e movimentos de dança, atualizando-as no corpo organizado, empírico.

A captura das forças demanda que o improvisador esteja atento e conectado ao plano das intensidades, dos afetos, das micro-percepções, plano que admitimos ser o spatium onde circulam as energias da criação do improviso de dança; um plano virtual co-presente que afeta o corpoconsciência do improvisador provocando a atualização de movimentos em perfeita sintonia com os sentidos que emergem na composição do improviso. Plano de consistência, este imperceptível imediatamente percebido (Deleuze \& Guattari, 1997, p.75), atualizado por uma consciência alargada, não intencional, não individualizada, anterior às representações, imagens, ideias e, portanto, incapaz de interpretar ${ }^{6}$.

Atua-se sobre o corpo físico de maneira a despertar a potência de um corpo intensivo, ou seja, do corpo-sem-órgãos, um corpo extremamente sutil e aberto às forças afetivas que circulam no plano de composição do improviso, criando a atmosfera para a dança. É para este corpo outro que olho quando passo a perceber diretamente o fluxo do improviso em mim e no outro; é este corpo que sinto quase tocar quando busco ver apenas o movimento; é neste corpo que percebo as relações em mim e com os outros; é com ele que posso, enfim, fluir na imanência da dança. Neste sentido, concordo com a afirmação de José Gil de que “Todo processo artístico supõe um corposem-órgãos" (Gil. 2008, p. 193), um plano de consistência, no qual as matérias de expressão interagem e se intensificam, libertando e criando forças, a ponto de transformarem a percepção do artista e também a do espectador nos encontros potentes que a arte lhes propicia.

\footnotetext{
6 A pesquisa de José Gil sobre a criação e a recepção da obra artística o levou a conceber uma noção de consciência alargada, intensificada pelas forças não-conscientes do corpo. Uma noção que não pode ser pensada dentro de tradição fenomenológica e que requer uma nova abordagem conceitual: "O processo de construção do objecto artístico não releva assim de uma descrição de actos da consciência. Mas, porque esta sofre modificações durante o processo, é de uma nova teoria da consciência que se requer (desde há muito) a elaboração. Uma teoria da consciência, e da consciência do corpo, da multiplicidade de consciências e de acontecimentos extrafenomenais que ocorrem na gênese e na recepção do objeto de arte" (2005, p.18).
} 


\section{Corpo paradoxal}

Com a consciência penetrada de corpo, o improvisador sente-se em um espaço paradoxal, ao mesmo tempo denso e fluído, aparentemente estável, mas essencialmente dinâmico. Isso se deve ao fato de seu corpo, ele mesmo "espacializado", criar espaço enquanto dança. O corpo-dançarino não está apenas no espaço como um objeto, ele é espaço (interno e externo) e cria espaço dançando.

Esse corpo compõe-se de uma matéria especial que tem a propriedade de ser no espaço e de devir espaço, quer dizer, de se combinar tão estreitamente com o espaço exterior que daí lhe advém texturas variadas: o corpo pode tornar-se um espaço interiorexterior produzindo então múltiplas formas de espaço, espaços porosos, esponjosos, lisos, estriados, espaços paradoxais de Escher ou de Penrose, ou muito simplesmente de simetria assimétrica, como a esquerda e a direita (num mesmo corpo-espaço). (Gil, 2004, p. 56).

A pele, como superfície aberta ao espaço exterior visível, mas também limite para um espaço interior invisível, faz a passagem entre o dentro e o fora, entretanto, quando afetada pela intensificação do corpo sutil, a consciência, não mais a reconhecendo como um limite claro para o corpo, passa a receber diretamente as energias produzidas pela mistura do dentro e do fora: "A pele deixa de delimitar o corpo próprio, estende-se para além dele no espaço exterior: é o espaço do corpo" (Gil, 2004, p. 63). A permeabilidade ao espaço interior - que Gil define como vazio, isto é, sem conteúdo consciente - possibilitada pela pele, transmutada pelas forças afetivas que circulam no espaço interior do corpo e penetrada de exterior, faz com que o corpo dançante se transforme em um tipo de corpo-superfície de Möbius (1790-1868): “Banda de Möbius que se forma à medida que absorve (máquina espaço interior-pele) as forças de afeto do interior e as faz circular pela superfí- cie" (Gil, 2004, p. 64)

Num corpo total, o interior se reverte ao exterior, a profundidade, antes ausente à consciência e enclausurada em um interior, sobe e se mistura à superfície como na Banda de Möbius: não há mais um dentro e um fora, o espaço interior afetivo emerge e se distribui pela superfície do corpo, as energias afetivas se esparramam pela pele - espaço de ubiqüidade, tornando o corpo todo presente, vivo e aberto à experimentação. O corpo, então, se dilata. Não se destacando de um espaço exterior como um objeto que o habita, este corpo potente, aumentado pelo seu poder de afirmar a dança, se alonga e se mistura aos outros corpos, ao meio. Seus gestos e movimentos ganham superfícies intensivas pelas quais se prolongam. Os limites se diluíram.

Gil afirma que o espaço do corpo não é um privilégio do dançarino, ator ou mesmo do esportista, pois todas as pessoas vivenciam-no em pequenas porções, sobretudo quando estão imersas no que estão fazendo. Os artistas da dança, por outro lado, têm a necessidade de criá-lo para a sustentação do gesto dançado; para eles, é preciso criar um meio que não ofereça resistência, em que a dança possa simplesmente fluir. Esse meio é o espaço do corpo que, ultrapassando os limites físicos da pele, se prolonga no espaço objetivo como virtualidades invisíveis. Nas palavras do filósofo: "Há um infinito próprio do gesto dançado que só o espaço do corpo pode engendrar" (2004, p. 53).

O corpo do improvisador dilata-se provocando uma alteração na percepção. Este corpo total criado pelo dançarinoimprovisador está expresso na noção de corpo paradoxal de José Gil, um corpo que ultrapassa os limites do corpo fenomenológico, o corpo visível no espaço objetivo de Descartes, ou melhor:

[...] um corpo metafenômeno, visível e virtual ao mesmo tempo, feixe de forças e transformador de espaço e de tempo, emissor de signos e transsemiótico, comportando um interior ao mesmo tempo orgânico e pronto a 
dissolver-se ao subir à superfície. Um corpo habitado por, e habitando outros corpos e outros espíritos, e existindo ao mesmo tempo na abertura permanente ao mundo por intermédio da linguagem e do contato sensível, e no recolhimento da sua singularidade, através do silêncio e da não-inscrição. Um corpo que se abre e que se fecha, que se conecta sem cessar com outros corpos e outros elementos, um corpo que pode ser desertado, esvaziado, roubado da sua alma e pode ser atravessado pelos fluxos mais exuberantes da vida. Um corpo humano porque pode devir animal, devir mineral, vegetal, devir atmosfera, buraco, oceano, devir puro movimento. Em suma, um corpo paradoxal. (Gil, 2004, p. 56).

Simultaneamente empírico-transcendental, extenso-intenso, presente-ausente, visível-invisível, exterior-interior, superfície-profundidade, consciente-inconsciente. O corpo paradoxal é este real-virtual que existe em estado de latência em todos os corpos empíricos constituídos (Gil, 2002, p. 145), e por isto, ele pode ser acessado, dinamizado, experimentado como pretendem as práticas energéticas, a meditação, o controle da respiração etc. Ele é anterior à cristalização das formas, dos órgãos, das imagens e pensamentos, mas, ao mesmo tempo, criado como corpo vibrante que atravessa e envolve a extensão do corpo comum. Neste corpo paradoxal, a consciência do dançarino-improvisador se deixa impregnar de corpo e o pensamento se mistura e se ajusta perfeitamente aos movimentos, facilitando a osmose com os outros corpos e matérias de expressão. O corpo paradoxal é, para Gil, o corpo empírico-transcendental de Deleuze, o CsO de Artaud: ao mesmo tempo virtual e atual, energético e físico. Ele cria um plano de consistência no qual a multiplicidade de movimentos em estado de vir a ser podem se agenciar às outras matérias de expressão. Nele, os muitos corpos potenciais do improvisador se misturam e se separam, alguns deles se destacam despertados pela atmosfera da criação da dança e são atualizados pelos improvisadores em suas composições.
A reversão do espaço interior ao exterior que cria um corpo Banda de Möbius, como nos sugere Gil, marca o esvaziamento dos estratos dominantes que modelam o corpo empírico, limitando-lhe a potência de vir a ser outros corpos em outros espaços e tempos virtuais. Parece-me que o trabalho energético facilita a reversão fazendo com que forças não-conscientes surjam do espaço interior do corpo, das profundidades de um espaço intensivo (spatium) e invisível, engendrando superfícies nas quais se exteriorizam tal como nos indica Deleuze, Guattari e Gil. Intensidades que se misturam aos poderes virtuais dos outros e que possibilitam a comunicação entre inconscientes (Gil, 2004), bem como a composição da dança no aqui-agora. A dilatação é a manifestação desta reversão, uma impregnação da consciência-corpo pelo movimento de dança.

Conhecer os poderes deste corpo é especialmente importante aos artistas, mas o mesmo pode ser afirmado para qualquer pessoa, uma vez que saber o que pode o corpo é um conhecimento prático que permite ao homem interferir diretamente na vida cotidiana, nos comportamentos, na maneira como lida com as emoções em si mesmo e nos outros, como se relaciona com os limites e como pode ultrapassá-los. Escavando no próprio corpo aprende-se a ver/sentir as forças em movimento no corpo sutil, mas na arte da composição imediata da dança é preciso também aprender a ver o sutil no outro, o invisível que pulsa e que o atravessa. Aprender a ver é saber criar ritmo com o outro (que é diferente de estar no ritmo do outro), é ter "ritmicidade" (Deleuze, 1981) nas relações com os outros; composição de tempos; osmose que faz consistir os heterogêneos (corpos, sons, cores...) na textura da imanência da dança.

O improvisador coloca-se no entrelugar, no intervalo e, assim, se mantém conectado às pequenas-percepções que pulsam entre o que está dado e o vir a ser, entre o determinado e o indeterminado, entre o caos e a forma. O entre é movimento, velocidade e lentidão, mobilidade; nele, a imanência pulsa e a dança simplesmente flui. 


\section{REFERENNCIAS}

BARBA, Eugenio; SAVARESE, Incola. A arte secreta do ator: dicionário de antropologia teatral. Tradução Luís Otávio Burnier. Campinas, SP: Hucitec, 1995. 271p.

DELEUZE, Gilles. Francis Bacon: Lógica da Sensação. Tradução Roberto Machado (coord.). Rio de Janeiro: Jorge Zahar, 2007. 183p.

Spinoza - Cours de Vincennes, 17/03/1981. Disponível na internet: http://www. webdeleuze.com/php/texte.php?cle $=43 \&$ groupe $=$ Spinoza\&langue $=1$. Data do último acesso: 25/05/2012.

DELEUZE, Gilles \& GUATTARI, Félix. Mil Platôs: capitalismo e esquizofrenia. Tradução Aurélio Guerra Neto, Ana Lúcia de Oliveira, Lúcia Cláudia Leão, Suely Rolnik. Volume 3. Rio de Janeiro: Editora 34, 1996. 115p.

. Mil Platôs: capitalismo e esquizofrenia. Tradução Suely Rolnik. Volume 4. São Paulo: Editora 34, 1997. 170p.

GIL, José. Movimento total: o corpo e a dança. São Paulo: Iluminuras, 2004. 223p.

. A imagem-nua e as pequenas percepções: Estética e Fenomenologia. Tradução Miguel Serras Pereira. Portugal, Lisboa: Relógio d'Água, 2a Edição, 2005. 330p.

. "O corpo paradoxal". In Nietzsche e Deleuze: que pode o corpo. Organização: Daniel Lins e Sylvio Gadelha (org.). Rio de Janeiro: Relume Dumará, Fortaleza, CE: Secretaria da Cultura e Desporto, 2002. P.131-147.

GOUVÊA, Raquel Valente de. Prática corporeoenergética para a improvisação de dança: uma via para a manifestação da criatividade. 2004. 197p. Dissertação (mestrado) - Universidade Estadual de Campinas, Instituto de Artes, Campinas, SP. Disponível na internet: http:/ / www.bibliotecadigital.unicamp.br/document $/$ ?code=000310058\&opt=1

. A improvisação de dança na (trans) formação do artista-aprendiz: uma reflexão nos entrelugares das Artes Cênicas, Filosofia e Educação. 2012. 174p. Tese (doutorado) - Universidade Estadual de Campinas, Faculdade de Educação, Campinas, SP.

LABAN, Rudolf. O domínio do movimento. Tradução A.M. De Vecchia e M.S. Netto. São Paulo: Summus, 1978. 268p. 